\title{
Discovery of $\mathrm{Fe}_{2} \mathrm{P}$-type $\mathrm{Ti}(\mathrm{Zr} / \mathrm{Hf})_{2} \mathrm{O}_{6}$ Photocatalysts toward Water Splitting
}

\author{
Xiangying Meng ${ }^{1, *}$, Lu Wang ${ }^{1}$, Dongyan liu ${ }^{1}$, Xiaohong Wen ${ }^{1}$, Qiang Zhu ${ }^{2, *}$, \\ William A. Goddard $\mathrm{III}^{3}$, Qi An ${ }^{3}$ \\ ${ }^{1}$ College of Sciences, Northeastern University, Shenyang 110819, China \\ ${ }^{2}$ Department of Geosciences and Department of Physics and Astronomy, State University of New \\ York, Stony Brook, NY 11794-2100, United States \\ ${ }^{3}$ Materials and Process Simulation Center, California Institute of Technology, Pasadena, CA \\ 91125, United States
}

*Correspondence and requests for materials should be addressed to X. Y. Meng or Q. Zhu (Email: x_y_meng@mail.neu.edu.cn; qiang.zhu@stonybrook.edu) 


\section{The crystallographic information (in .cif format) for $\mathrm{TiZr}_{2} \mathrm{O}_{6}$}

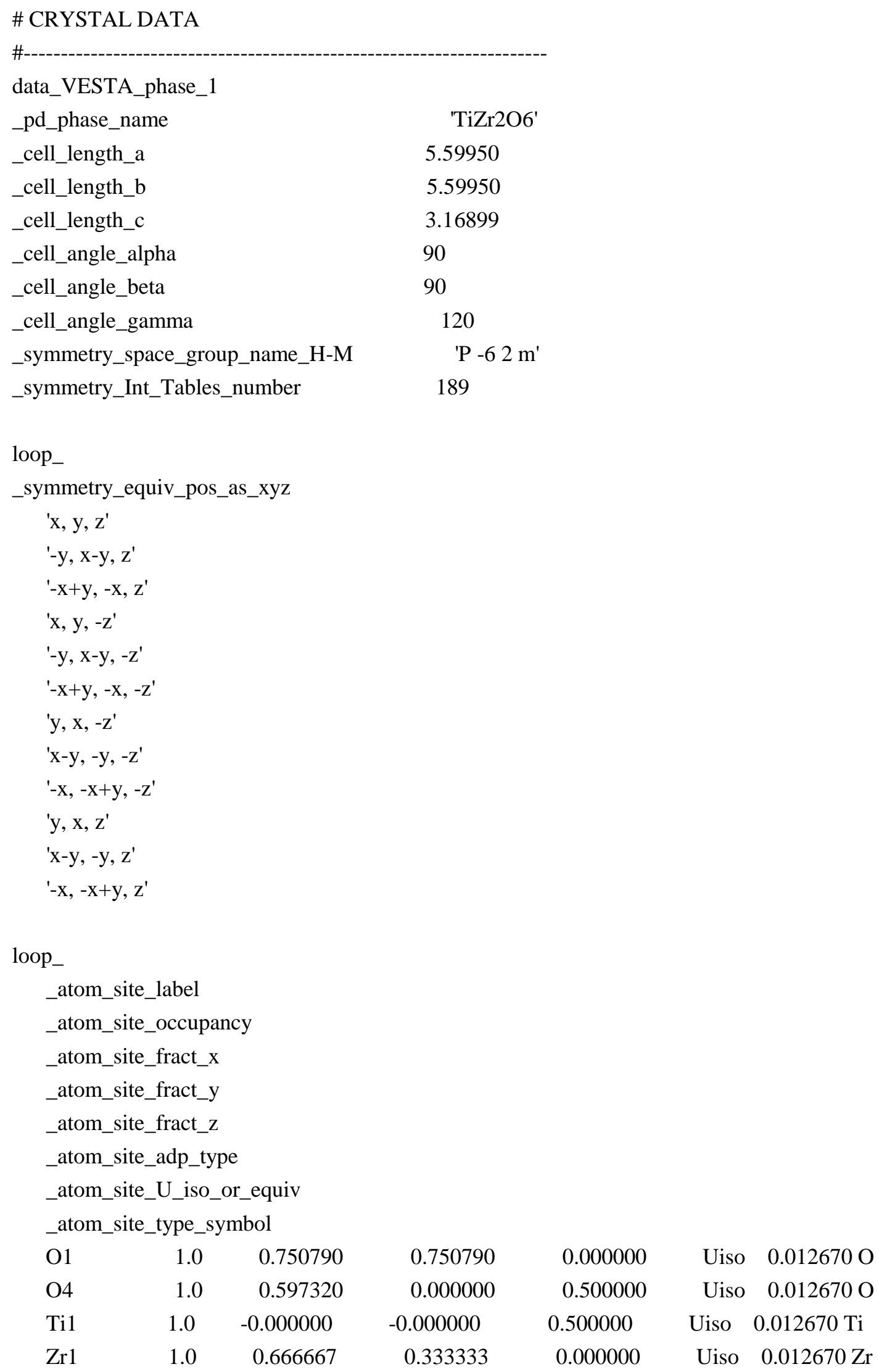

$\begin{array}{lcccccc}\text { O1 } & 1.0 & 0.750790 & 0.750790 & 0.000000 & \text { Uiso } & 0.012670 \mathrm{O} \\ \mathrm{O} 4 & 1.0 & 0.597320 & 0.000000 & 0.500000 & \text { Uiso } & 0.012670 \mathrm{O} \\ \mathrm{T} 1 & 1.0 & -0.000000 & -0.000000 & 0.500000 & \text { Uiso } & 0.012670 \mathrm{Ti} \\ \mathrm{Zr} 1 & 1.0 & 0.666667 & 0.333333 & 0.000000 & \text { Uiso } & 0.012670 \mathrm{Zr}\end{array}$




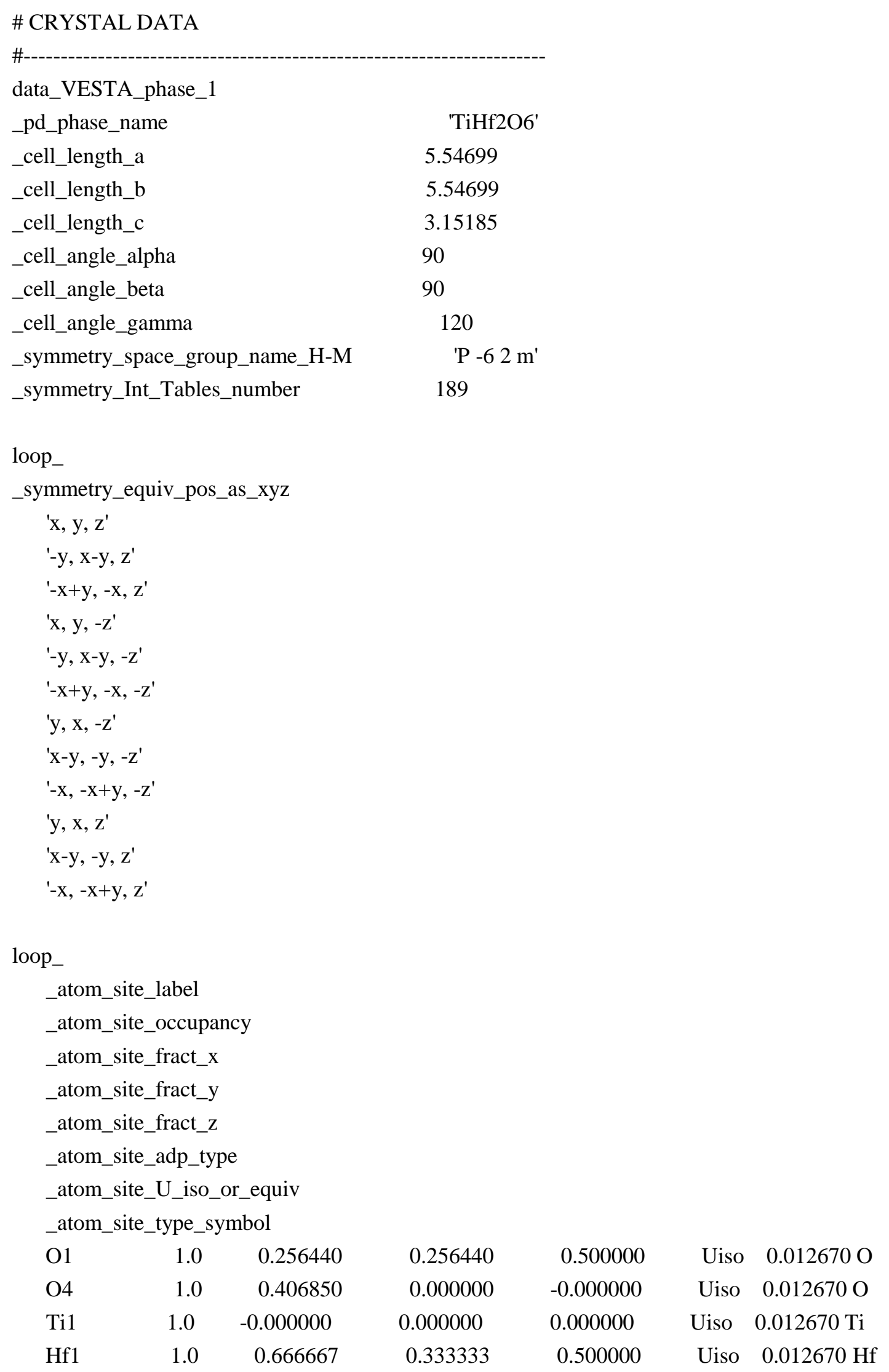

$\begin{array}{lcccccc}\text { O1 } & 1.0 & 0.256440 & 0.256440 & 0.500000 & \text { Uiso } & 0.012670 \mathrm{O} \\ \mathrm{O} 4 & 1.0 & 0.406850 & 0.000000 & -0.000000 & \text { Uiso } & 0.012670 \mathrm{O} \\ \text { Ti1 } & 1.0 & -0.000000 & 0.000000 & 0.000000 & \text { Uiso } & 0.012670 \mathrm{Ti} \\ \mathrm{Hf} 1 & 1.0 & 0.666667 & 0.333333 & 0.500000 & \text { Uiso } & 0.012670 \mathrm{Hf}\end{array}$




\section{The elastic constants and modulus of $\mathrm{Ti}(\mathrm{Zr} / \mathrm{Hf})_{2} \mathrm{O}_{6}$}

Based on the energy-strain relations, the independent elastic constants of $\mathrm{Ti}(\mathrm{Zr} / \mathrm{Hf})_{2} \mathrm{O}_{6}$ at the zero-pressure are calculated and listed in Table 1s. It is clear that the calculated elastic constants of $\mathrm{Ti}(\mathrm{Zr} / \mathrm{Hf})_{2} \mathrm{O}_{6}$ fulfill the mechanical stability criteria: $\mathrm{C}_{44}>0, \mathrm{C}_{11}>\left|\mathrm{C}_{12}\right|$, and $\left(\mathrm{C}_{11}+\mathrm{C}_{12}\right) \mathrm{C}_{33}>2 \mathrm{C}_{12}^{2}$.

\section{The phonon dispersion curves at $0 \mathrm{GPa}$ of $\mathrm{Fe}_{2} \mathrm{P}$-type $\mathrm{ZrO}_{2}$ and $\mathrm{HfO}_{2}$}

In Fig. 1s_a, no imaginary phonon frequency is observed in $\mathrm{Fe}_{2} \mathrm{P}$-type $\mathrm{ZrO}_{2}$ at 0 $\mathrm{GPa}$, indicating its dynamical instability at ambient conditions. However, in $\mathrm{Fe}_{2} \mathrm{P}$-type $\mathrm{HfO}_{2}$ (Fig. 1s_b), an acoustic phonon branch is found negative. The dynamical stability of $\mathrm{Fe}_{2} \mathrm{P}$-type at ambient conditions need to be further investigated by both theoretical and experimental studies.

\section{HSE band structures at $0 \mathrm{GPa}$ of $\mathrm{Fe}_{2} \mathrm{P}$-type $\mathrm{ZrO}_{2}$ and $\mathrm{HfO}_{2}$}

HSE obtained band structures of $\mathrm{ZrO}_{2}$ and $\mathrm{HfO}_{2}$ are shown in Fig. 2s. The present calculations give bandgaps of $2.64 \mathrm{eV}$ and $3.00 \mathrm{eV}$ for $\mathrm{Fe}_{2} \mathrm{P}$-type $\mathrm{ZrO}_{2}$ and $\mathrm{HfO}_{2}$, respectively. The ionicity for the $\mathrm{Fe}_{2} \mathrm{P}$-type compounds is listed in Table $2 \mathrm{~s}$. The bandgap of $\mathrm{Fe}_{2} \mathrm{P}$-type IVa-oxides is found to be wider and wider with the increase of the ioncity.

Table S1. The independent elastic constants and modulus (bulk modulus $B$, shear modulus $G$, Young's modulus $E$, and Poisson's ratio $v$ ) of $\mathrm{Ti}(\mathrm{Zr} / \mathrm{Hf})_{2} \mathrm{O}_{6}$. All elastic parameters except $v$ are in GPa.

\begin{tabular}{cccccccccccc}
\hline & $C_{11}$ & $C_{33}$ & $C_{44}$ & $C_{66}$ & $C_{12}$ & $C_{13}$ & $B$ & $G$ & $E$ & $v$ & $B / G$ \\
\hline $\mathrm{TiZr}_{2} \mathrm{O}_{6}$ & 458 & 424 & 124 & 124 & 250 & 175 & 281 & 115 & 305 & 0.32 & 2.43 \\
$\mathrm{TiHf}_{2} \mathrm{O}_{6}$ & 475 & 442 & 132 & 102 & 269 & 177 & 291 & 119 & 314 & 0.32 & 2.45 \\
\hline
\end{tabular}

Table S2. The ionicity and HSE bandgap $(\mathrm{eV})$ of $\mathrm{Fe}_{2} \mathrm{P}$-type IVa-oxides.

\begin{tabular}{lccccc}
\hline & $\mathrm{TiO}_{2}$ & $\mathrm{TiZr}_{2} \mathrm{O}_{6}$ & $\mathrm{ZrO}_{2}$ & $\mathrm{TiHf}_{2} \mathrm{O}_{6}$ & $\mathrm{HfO}_{2}$ \\
\hline Ionicity & $39 \%$ & $42 \%$ & $44 \%$ & $45 \%$ & $48 \%$ \\
HSE Bandgap & 2.00 & 2.29 & 2.64 & 2.65 & 3.00 \\
\hline
\end{tabular}




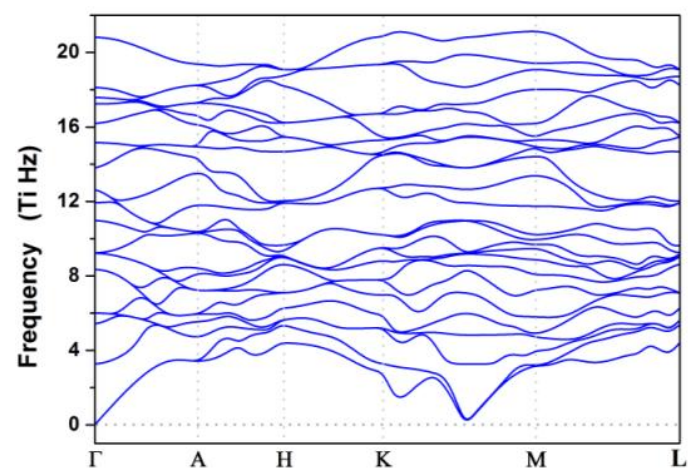

(a)

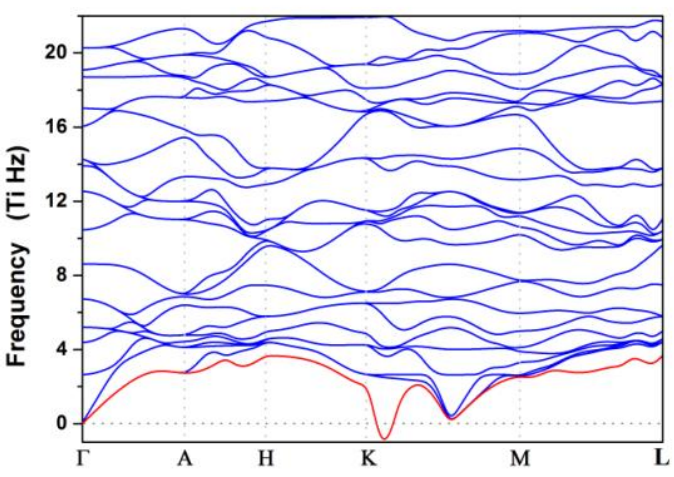

(b)

Figure S1. Phonon dispersion curves for $\mathrm{Fe}_{2} \mathrm{P}$-type $\mathrm{ZrO}_{2}$ (a) and $\mathrm{HfO}_{2}$ (b) at $0 \mathrm{GPa}$

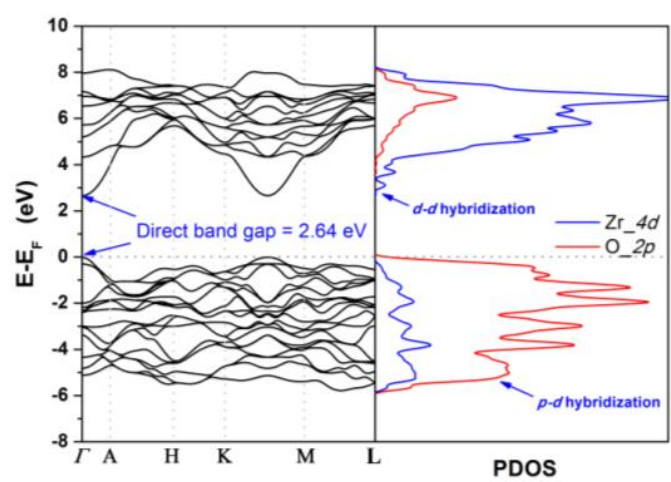

(a)

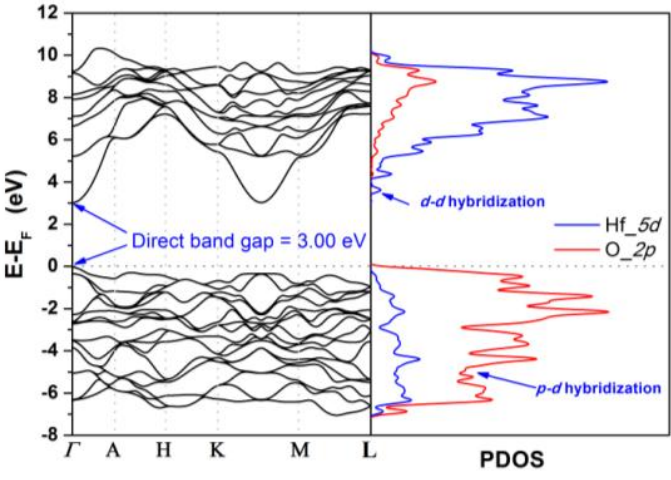

(b)

Figure S2. HSE band structure of $\mathrm{Fe}_{2} \mathrm{P}$-type $\mathrm{ZrO}_{2}$ (a) and $\mathrm{HfO}_{2}$ (b) at $0 \mathrm{GPa}$ 